\title{
Kepemimpinan Pendidikan Masa Pandemi Covid-19 Pada Pendidikan Anak Usia Dini
}

\author{
Wresni Pujiyati \\ Manajemen Pendidikan, Universitas Wiralodra, Indonesia \\ DOI: $\underline{10.31004 / \text { obsesi.v6i3.1804 }}$
}

\begin{abstract}
Abstrak
Pembentukan kualitas dan pencapaian kesiapan belajar adalah salah satu dari peran kepemimpinan yaitu memberikan pengaruh arah dan arahan kepada anggotanya. Tujuan penelitian ini untuk mengetahui dan menganalisa kepemimpinan pada Pendidikan Anak Usia Dini (PAUD). Menggunakan pendekatan kualitatif dengan metode studi kasus. Responden penelitian ini adalah kepala sekolah, guru, dan stakeholder eksternal di wilayah Indramayu Jawa Barat. Temuan di lapangan menunjukkan bahwa masih ditemukan guru yang kurang termotivasi. Hal ini dikarenakan kurikulum yang belum sesuai, proses pembelajaran yang tidak maksimal, serta pembiayaan yang tidak memadai. Kepemimpinan pada PAUD sangat dibutuhkan kebijaksanaan dan kecendekiaan untuk mencapai kualitas pendidik, selain adanya pelatihan yang terus menerus dan berkesinambungan. Dapat diimplementasikan keefektifannya melalui perencanaan, pengorganisasian, pengarahan dan pengawasan. Faktor ini dikaitkan dengan hasil belajar siswa dan kurikulum, proses pembelajaran, dan metode pengajaran. Keefektifan tersebut dikaitkan dengan hasil belajar siswa dan kurikulum, proses pembelajaran, dan metode pengajaran dilaksanakan bersama guru dan wali murid serta unsur sekolah.
\end{abstract}

Kata Kunci: pendidikan anak usia dini; covid-19; Kepemimpinan pendidikan.

\begin{abstract}
Education is an attempt to acquire knowledge, Early Childhood Education (PAUD) is part of a person's basic education to achieve educational success at the next level. The formation of quality and achievement of learning readiness is one of the roles of leadership. The purpose of this study was to determine and analyze leadership in PAUD. Uses a qualitative approach with a case study method. The respondent of this study were principal, teacher, and external stakeholder in the Indramayu area of West Java. Findings in the field show that there are still teachers who are less motivated. This is because the curriculum is not appropriate, the learning process is not optimal, and the funding is inadequate. The conclusion is that educational leadership in PAUD should have wisdom, vision, and intelligence to train people to think clearly and fairly. Leadership can be implemented effectively through planning, organizing, directing and monitoring. These factors are associated with student learning outcomes and curriculum, learning process, and teaching methods. Planning, organizing, directing, and supervising related to student learning outcomes and curriculum, learning processes, and teaching methods are carried out together with teachers and guardians of students as well as school elements.
\end{abstract}

Keywords: early childhood education; covid-19; educational leadership.

Copyright (c) 2021 Wresni Pujiyati

$\triangle$ Corresponding author:

Email Address : wresni.pujiyati@gmail.com

Received 5 July 2021, Accepted 13 October 2021, Published 9 November 2021

Jurnal Obsesi : Jurnal Pendidikan Anak Usia Dini, 6(3), 2022 | 1907 


\section{PENDAHULUAN}

Mengacu pada program OECD pada PISA (Programme for Interntional Student Assessment) yaitu suatu program yang menyusun penilaian/asesmen siswa internasional berdasar skor reading, mathematic, dan science. Program ini dapat dianalisa bahwa membaca, berhitung, dan sains merupakan esensi belajar. Sedangkan belajar adalah usaha untuk memperoleh kepandaian (KBBI daring). Belajar adalah proses untuk mempelajari. Dalam proses mempelajari ini, diperoleh pengalaman dalam pengetahuan, perilaku, keterampilan, dan sikap (Morrison, 2012). Salah satu cara untuk mendapatkan pengalaman tersebut adalah melalui pendidikan. Penelitian yang relevan tentang kendala proses belajar adalah komunikasi dengan guru yang terhambat rendahnya tingkat ketersediaan perangkat teknologi informasi, perilaku anak yang berbeda (moody), ketidaksiapan menerima perubahan (Wardani \& Ayriza, 2020)

Pendidikan dimaksudkan sebagai suatu cara untuk menumbuh kembangkan potensi, seperti tertuang dalam Undang-Undang Sisdiknas Nomor 20 Tahun 2003. Pasal 28 C Ayat 2 Undang-Undang Sisdiknas Nomor 20 Tahun 2003 dinyatakan bahwa setiap anak berhak mengembangkan diri melalui pemenuhan kebutuhan dasarnya, berhak mendapatkan pendidikan dan memperoleh manfaat dari ilmu pengetahuan dan teknologi seni dan budaya, demi meningkatkan kualitas hidupnya dan demi kesejahtaraan umat manusia. Pengasuhan anak akan menyiapkan mereka dalam perkembangan kognitif. Selain itu, pengasuhan anak akan membantu mereka ikut serta dalam proses belajar yang dimulai sejak lahir (Morrison, 2012). Sejalan dengan pendapat tersebut, bahwa anak usia dini memiliki keunikan yang perlu diperhatikan sehingga perlu pelayanan yang sungguh-sungguh dalam pelayanan dan bimbingan (Suryana, 2013). Untuk itu dibutuhkan pengelola pendidikan agar sekolah menjadi berkualitas. Untuk mewujudkan kualitas sekolah, dibutuhkan kepemimpinan pendidikan (Ekosiswoyo, 2016)

Pandemi covid-19 telah mengubah segalanya, sebagai contoh bidang ekonomi (Allen \& Mirsaeidi, 2020), kehidupan sosial (Harahap, 2020), maupun pendidikan (James \& Thériault, 2020). PAUD pada masa pandemi covid-19 salah satunya juga terdampak (Dias et al., 2020). Dampak tersebut adalah kurang maksimalnya penyampaian materi (Satrianingrum \& Prasetyo, 2021). Salah satu solusinya adalah pembelajaran daring (Sudrajat et al., 2020). Lembaga. Keberhasilan suatu lembaga pendidikan salah satunya ditentukan oleh kepemimpinan pendidikan (Nasution, 2016). Penelitian terdahulu oleh (Supriadi, 2020) tentang peranan kepala PAUD dalam penyelenggaraan pendidikan sebelum dan saat terjadi pandemi covid-19 menunjukkan bahwa peranan kepemimpinan kepala sekolah sangat tinggi.

Moore, mengidentifikasi Kepemimpinan adalah kemampuan untuk mengesankan keinginan pada mereka yang dipimpin dan mendorong kepatuhan, rasa hormat, kesetiaan, dan kerja sama. Kepemimpinan adalah proses individu mempengaruhi kelompok (Northouse, 2021). meliputi aspek-aspek sebagai berikut yaitu mempengaruhi, membimbing, mengkoordinasikan, dan menggerakkan (Duryat, 2016). Kepemimpinan pendidikan oleh Robinson dideskripsikan sebagai kepemimpinan yang menyebabkan orang lain melakukan sesuatu yang diharapkan untuk meningkatkan hasil pendidikan (Thornton, 2014). Namun, ditemukan dilapangan masih adanya guru yang kurang termotivasi dalam pekerjaannya. Hal ini berakibat tidak maksimalnya guru dalam melaksanakan tugasnya. Dengan kata lain, belum sesuai dengan yang diharapkan.

Kepemimpinan pendidikan merupakan kemampuan untuk mencapai tujuan yang telah ditetapkan dengan menggerakkan pelaksanaan pendidikan secara efektif dan efisien (Afriansyah \& Pratiwi, 2020). Kepemimpinan pendidikan jika dalam konteks perbaikan sekolah serta untuk pembelajaran siswa, dibutuhkan "backward-mapping way" istilah yang digunakan Dimmock mendeskripsikan (Brundrett et al., 2003). Backward-mapping way atau "cara pemetaan mundur" adalah mengidentifikasi, mengaitkan hasil belajar siswa dengan kurikulum, proses pembelajaran, metode pengajaran, struktur organisasi, keuangan, manajemen sumber daya manusia, dan membangun budaya. 
Pendidikan pada Lembaga PAUD penekanannya pada karakter, karena membina anak usia 0 - 6 tahun (Baharuddin et al., 2017). Elemen kepemimpinan pendidikan yang tidak bertanggung jawab adalah ketidaksadaran emosional dan regulasi emosi yang buruk, pandangan sempit tentang pendidikan, pandangan seperti bisnis hubungan guru-siswa, pandangan Narsisis dan egosentris, membuat keputusan yang berpusat pada diri sendiri (Oplatka, 2016). Sedangkan pendidikan anak usia dini harus diselenggarakan sebaik-baiknya melalui perencanaan, pengorganisasi, pengarahan, dan pengawasan yang berkesinambungan dan sistematis (Pranita et al., 2018). Kepemimpinan pada dasarnya adalah menangani perubahan, menciptakan visi dan melibatkan individu. Kegiatan tersebut untuk mengatasi situasi yang dinamis (Alban-Metcalfe \& Alimo-Metcalfe, 2013). Untuk memperlancar kegiatan pembelajaran, kepemimpinan kepala sekolah mempunyai peran yang sangat menentukan (Sudrajat et al., 2020). Mulyasa mendeskripsikan peran utama kepemimpinan kepala sekolah adalah sebagai edukator, manajer, administrator, supervisor, leader, inovator, dan motivator (Supriadi, 2020). Penelitian terdahulu tentang kepemimpinan pada PAUD bahwa kepala sekolah perlu menerapkan langkah strategis agar sekolah berkualitas (Sudrajat et al., 2020). Sedangkan penelitian ini berusaha mengungkap bagaimana kepemimpinan pada PAUD di masa pandemi covid-19.

\section{Kajian terhadap hasil penelitian terdahulu tentang kepemimpinan pada PAUD}

Kajian terhadap hasil penelitian terdahulu tentang kepemimpinan pada PAUD dengan judul "Pengaruh Gaya Kepemimpinan dan Budaya Kerja Kepala Sekolah di Pendidikan Anak Usia Dini" oleh Novianty Djafri (2020). Jurnal Obsesi: Jurnal Pendidikan Anak Usia Dini, 4(2), 940-950. Menurut Novianty Djafri, budaya kerja yang positif, akan meningkatkan gaya kepemimpinan kepala sekolah PAUD bersama bawahan dan anggota serta unsur sekolah yaitu pemerintah yang membidangi pengelolaan PAUD, guru, orangtua, siswa-siswi, dan maysarakat (Djafri, 2020). Penelitian Novianty bertujuan mengetahui Pengaruh Gaya Kepemimpinan dan Budaya Kerja Kepala Sekolah di Pendidikan Anak Usia Dini. Penelitian Novianty terkait dengan kepemimpinan PAUD dan Budaya Kerja, sedangkan peneliti melakukan penelitian tentang Kepemimpinan PAUD di Kabupaten Indramayu Jawa Barat dengan aspek perencanaan, pengorganisasian, pengarahan, dan pengawasan. Serta dikaitkan dengan hasil belajar siswa dan kurikulum, proses pembelajaran, dan metode mengajar.

Kajian lainnya terhadap hasil penelitian terdahulu dengan judul "Constructing early childhood leadership models in China: a mixed-methods study (Membangun model kepemimpinan anak usia dini di Cina: studi metode campuran) oleh Mo Wang, Dora Ho, Jiafang Lu and Dongmei Yang (2020). Journal of Educational Administration, 2020 - emerald.com. Menurut Wang, dkk., bahwa terdapat tiga faktor pada kepemimpinan PAUD, yaitu manajemen dan pengembangan staf, pembelajaran dan dukungan sebaya serta komunikasi dengan orang tua. Penelitian Wang dkk., bertujuan untuk Tujuan dari penelitian ini adalah untuk membangun skala untuk mengukur kepemimpinan anak usia dini di Cina. Perbedaan penelitian Wang dkk., dengan penelitian ini adalah penggunaan metode penelitian. Wang dkk., menggunakan pendekatan kualitatif dan kuantitatif (mix method). Wang dkk. menggunakan faktor manajemen dan pengembangan staff, pembelajaran dan dukungan sebaya, dan komunikasi dengan orang tua untuk mengukur kepemimpinan pada PAUD (Wang et al., 2020). Sedangkan penelitian ini dilaksanakan di Kabupaten Indramayu-Jawa Barat, Indonesia, menggunakan faktor perencanaan, pengorganisasian, pengarahan, pengawasan. Faktor ini dikaitkan dengan hasil belajar siswa dengan kurikulum, proses pembelajaran, dan metode pengajaran.

Kajian hasil penelitian terdahulu tentang kepemimpinan pada PAUD yang lain adalah "Prekindergarten Interventions and Instructional Leadership in Small and Mid-Sized Urban School Districts" (Intervensi Pendidikn Anak Usia Dini dan Kepemimpinan Instruksional di Distrik Sekolah Perkotaan Kecil dan Menengah) oleh Raleta C. Summers and Ian E. Sutherland (2015). (Summers \& Sutherland, 2015). Emerald Group Publishing Limited. Penelitian Summers \& 
Sutherland, 2015 bertujuan untuk mengkaji tantangan kepemimpinan instruksional dalam program taman kanak-kanak (PK) dalam konteks sekolah kecil dan sekolah menengah di kabupaten. Sedangkan penelitian ini mengkaji tentang kepemimpinan pada PAUD di Kabupaten Indramayu_Jawa Barat, Indonesia.

\section{METODOLOGI}

Penelitian ini menggunakan pendekatan kualitatif dengan metode studi kasus. Partisipan dalam penelitian adalah kepala sekolah, guru, stakeholder. Kisi-kisi penelitian tercantum pada tabel 1 .

Tabel 1. Kisi-Kisi Penelitian

\begin{tabular}{|c|c|c|}
\hline Fokus Penelitian & Metode & Pedoman \\
\hline $\begin{array}{c}\text { Memiliki kearifan } \\
\text { Visi } \\
\text { Melatih }\end{array}$ & $\begin{array}{c}\text { Wawancara } \\
\text { Observasi } \\
\text { Studi Dokumen }\end{array}$ & $\begin{array}{c}\text { Pedoman wawancara } \\
\text { Pedoman untuk catatan dokumen } \\
\text { berdasarkan kegiatan yang dilaksanakan, } \\
\text { catatan observasi } \\
\end{array}$ \\
\hline
\end{tabular}

Tabel 1 mendeskripsikan kisi-kisi penelitian dengan fokus penelitian adalah kepemimpinan dengan fokus pemimpin memiliki kearifan, visi, kecerdasan untuk melatih orang berpikir jerih dan adil bagi diri mereka sendiri dan orang lain. Metode pengumpulan data melalui wawancara, observasi, dan studi dokumen.

Tabel 2. Operasional Pengembangan Instrumen Penelitian

\begin{tabular}{llll}
\hline Kategori & Metode & Sumber Data & Pedoman \\
\hline Kurikulum & & & \\
Proses Pembelajaran & Wawancara & Pimpinan & Pedoman \\
Metode Pengajaran & Observasi & Guru & Wawancara \\
Struktur Organisasi & Studi Dokumen & Stakeholder & \\
Keuangan & & & \\
\hline
\end{tabular}

Operasional pengembangan instrumen penelitian disajikan pada tabel 2 mendeskripsikan kategori dalam operasional pengembangan instrumen penelitian. Operasional pengembangan instrumen dalam penelitian ini yaitu kurikulum, proses pembelajaran, metode pengajaran, struktur organisasi, keuangan. Kategori tersebut disusun dalam instrumen sebagai pedoman wawancara melalui metode wawancara, observasi, dan studi dokumen. Responden atau sumber data penelitian adalah pimpinan, guru, dan masyarakat atau stakeholder eksternal.

Tabel 3. Teknik Wawancara

\begin{tabular}{ccc}
\hline $\begin{array}{c}\text { Tujuan } \\
\text { Berdasarkan } \\
\text { Fokus Penelitian }\end{array}$ & Wawancara & Studi Dokumen \\
\hline $\begin{array}{c}\text { Memiliki Kearifan } \\
\text { Visi }\end{array}$ & $\begin{array}{c}\text { Alat: pedoman wawancara } \\
\text { Jenis: wawancara semi } \\
\text { Melatih }\end{array}$ & $\begin{array}{c}\text { Alat: pedoman studi dokumentasi } \\
\text { terstuktur dengan pedoman } \\
\text { Informan: pimpinan, guru, } \\
\text { stakeholder }\end{array}$ \\
$\begin{array}{c}\text { data statistik, dan data kualitatif lainnya } \\
\text { Bentuk dokumentasi: copy dokumen, } \\
\text { foto, memo, image capture, media sosial } \\
\text { dan media lainnya }\end{array}$ \\
\hline
\end{tabular}


Tabel 3 mendeskripsikan teknik wawancara yaitu berdasarkan fokus penelitian. Metode yang digunakan selain observasi adalah wawancara dan studi dokumen. Wawancara menggunakan pedoman wawancara yang telah disusun berdasar fokus penelitian. Studi dokumen melalui dokumen resmi, foto, data statistik, dan data-data yang terkait dengan fokus penelitian.

Analisis data yang digunakan berdasarkan analisis Miles, Huberman, dan Saldana tahun 2014 terdiri dari 3 kegiatan yang saling berintekasi, yaitu reduksi data, penyajian data penarikan kesimpulan atau verifikasi (Usman \& Akbar, 2018). Reduksi data dilakukan dengan mengumpulkan data kemudian mereduksi, yaitu memilah hal-hal yang sesuai dengan fokus penelitian, kemudian dicari temanya. Penyajian data dilakukan dengan diawali dari catatan lapangan yang kemudian diorganisasikan dan disajikan dalam bentuk teks naratif, bagan, matriks, grafik, jaringan. Setelah itu penarikan kesimpulan atau verifikasi yaitu melakukan verifikasi baik makna maupun kebenaran yang disepakati oleh subjek tempat penelitian dengan menguji kebenaran, kecocokan, dan kekokohannya. Skema prosedur penelitian dideskripsikan pada gambar 1 .

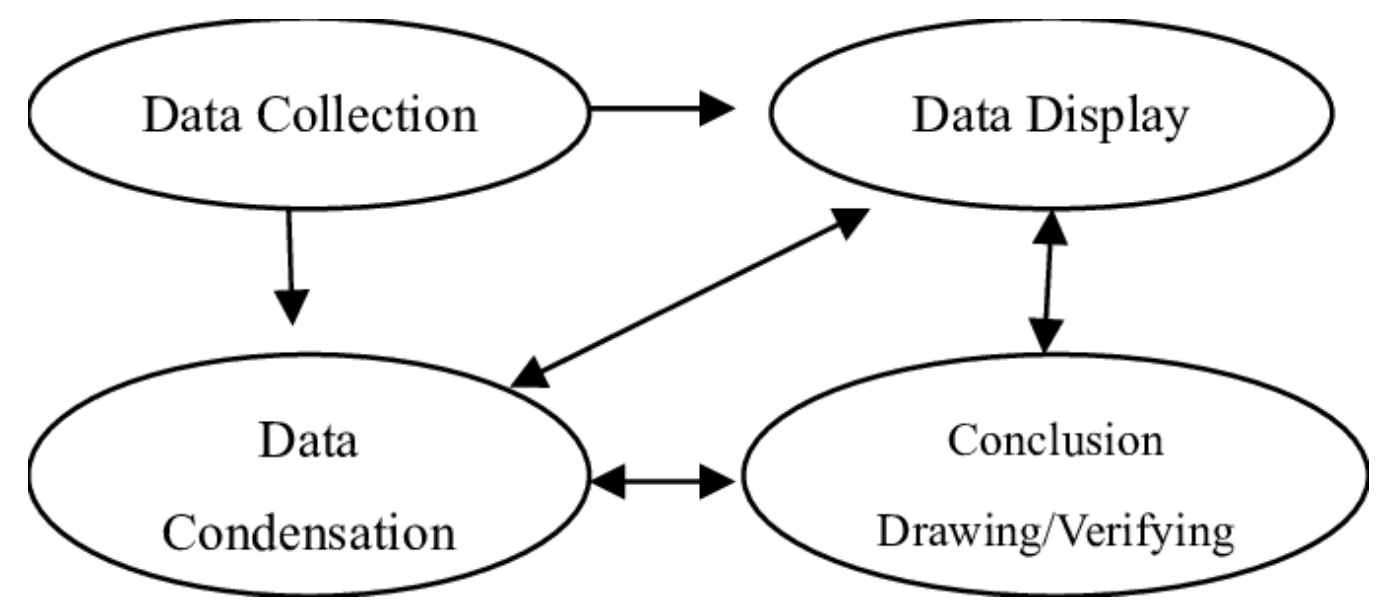

Gambar 1 Model Interaktif (Miles, Huberman, Saldana, 2014)

Peneliti membuat sistem pengkodean (koding) untuk memudahkan dalam mengidentifikasi unit informasi. Pengkodean ini dimaksudkan untuk mempermudah dalam mengidentifkasi hasil wawancara. Tabel 4 mendeskripsikan pengkodean pada penelitian ini.

Tabel 4 Pengkodean Hasil Wawancara

\begin{tabular}{ccc}
\hline Nomor & Partisipan & Kode \\
\hline 1 & Pimpinan & P.IMY.W.XX \\
2 & Guru & G.BY.W.XX \\
3 & Stakeholder & S.BY.W.XX \\
\hline
\end{tabular}

Keterangan Tabel 4 kode $\mathrm{P}$ adalah pimpinan, $\mathrm{G}$ adalah guru, $\mathrm{S}$ adalah stakeholder. Sedangkan IMY adalah Indramayu, yaitu lokasi penelitian. $\mathrm{W}$ adalah wawancara, XX Nomor urut.

Pemeriksaan keabsahan data dilakukan dengan teknik perpanjangan keikutsertaan peneliti, ketekunan/keajegan pengamatan, dan triangulasi. Perpanjangan keikutsertaan peneliti, ketekunan/keajegan pengamatan dilakukan peneliti dengan hadir dilokasi guna menyelami budaya dan lokasi penelitian. Peneliti melakukan ini di lokasi penelitian dari bulan Januari 2021 sampai dengan Juni 2021. Perpanjangan dengan tujuan keajegan pengamatan dilakukan pada Juni 2021 sampai dengan September 2021. 


\section{HASIL DAN PEMBAHASAN}

Penelitian dilakukan dengan cara melakukan wawancara kepada responden tentang kurikulum, proses pembelajaran, dan metode pengajaran. Wawancara tentang kurikulum, proses pmbelajaran, dan metode pengajaran ini dikaitkan dengan perencanaan, pengorganisasian, pengarahan, dan pengawasan.

Hasil wawancara pada kurikulum oleh informan P.IMY.W.XX menyatakan bahwa "kurikulum masih belum terpenuhi. Proses pembelajaran belum efektifkarena kemampuan tutor masih rendah. Sedangkan metode pengajaran belum variatif. Metode pengajaran belum variatif, masih monoton, tutor tidak mengacu pada kurikulum. Struktur organisasi masih belum optimal. Keuangan masih berharap pada dana bantuan pemerintah"... (Kode: P.IMY.W.XX, 21 Januari 2021).

Hasil wawancara dengan informan G.IMY.W.XX diperoleh informasi bahwa "kami mengunakan panduan kurikulum dari kemenag yaitu KTSP 2016 berlandaskan nilai-nilai islami. Proses pembelajaran menggunakan pendekatan klasikal dan kelompok. Kami menggunakan metode bercerita, bernyanyi, sosio drama, demonstrasi, tanya jawab, pemberian tugas"... (kode: G.IMY.W.XX, 2 Februari, 2021)

Hasil wawancara dengan informan S.IMY.W.XX menyatakan bahwa "guru-guru pendidikannya hanya sampai tingkatan SMA dan 1 orang S1 PAI".... (kode: S.IMY.W.XX, 2 Februari 2021)

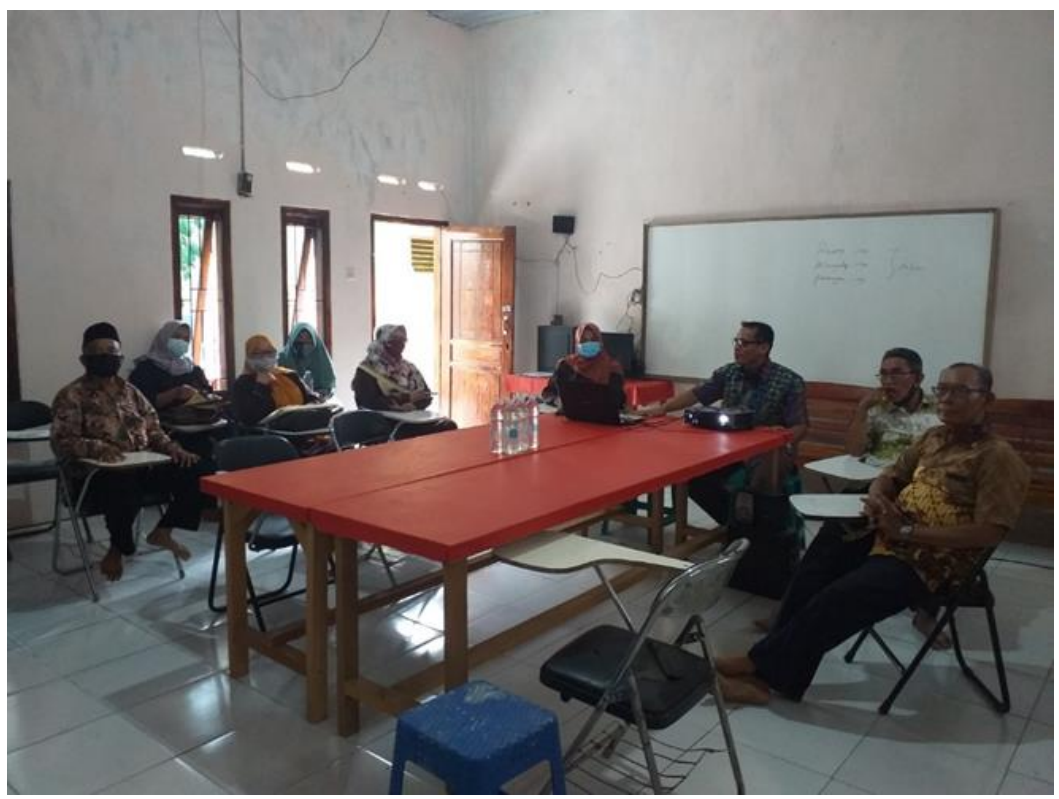

Gambar 2 Rapat Guru PAUD dan Pimpinan

Gambar 2 menunjukkan adanya rapat guru PAUD dan pimpinan. Rapat terdiri dari stakeholder, guru, dan pimpinan. Ini mengindikasikan bahwa pimpinan telah melaksanakan komunikasi dalam pengarahannya. Pemimpin yang memiliki kearifan sangat dibutuhkan dalam sebuah lembaga pendidikan. Kearifan diartikan sebagai kebijaksanaan; kecendekiaan (KBBI).

\section{Kurikulum}

Kurikulum setiap prasekolah berbeda dan dipengaruhi oleh standar negara. Prasekolah berkualitas sebagian besar merencanakan tujuan di bidang-bidang berikut: keterampilan sosial dan interpersonal, keterampilan bantuan diri dan intrapersonal, belajar cara belajar dan mengembangkan kecintaan akan belajar, guru, kemampuan berpikir, kesiapan belajar, bahasa, dan kemampuan baca-tulis, pendidikan kepribadian, musik dan seni, kesejahteraan dan hidup sehat, dan kemandirian (Morrison, 2012). 
Mengacu pada Froebel, bahwa anak belajar dan berkembang lewat permainan, serta teori Montessori yang melihat keikutsertaan aktif anak dalam materi dan lingkungan yang telah disiapkan sebagai sarana anak untuk memperoleh pengetahuan. Selain itu, teori John Dewey bahwa anak belajar lewat permainan untuk itu anak haus mendapat kesempatan untuk ikut dalam permainan yang berhubungan dengan kegiatan sehari-hari. Teori Piaget tentang pengetahuan kognitif, serta Vygotsky yang meyakini interaksi sosial penting bagi anak untuk perkembangannya. Bidang-bidang kurikulum untuk prasekolah sasarannya pada keterampilan, kesiapan, akademik, bahasa dan baca tulis, pendidikan karakter, kesejahteraan dan kehidupan yang sehat, kemandirian, musik dan seni (Morrison, 2012).

Kurikulum yang masih belum terpenuhi karena sumber daya yang belum memadai seperti harapan, solusinya melalui pemaksimalan standar pengelolaan PAUD, yaitu perencanaan program, pengorganisasian, pelaksanaan rencana kerja, dan pengawasan (SN PAUD).

Sejalan dengan penelitian Bustami, dkk. Dengan judul “Manajemen Pendidikan PAUD Al-Fath Sabang" bahwa pada perencanaan yang dilakukan adalah menyusun rencana kegiatan sesuai ketentuan dengan melibatkan guru dan masyarakat, kepala sekolah. Pengorganisasian dilakukan melalui adanya relevansi antara kemampuan dan keterampilan, serta terjalinnya koordinasi antara pimpinan-bawahan. Pengawasan dilakukan secara langsung dan pengawasan fungsional. Pengawasan langsung dilaksanakan oleh kepala sekolah, pengawasan fungsional dilaksanakan oleh pengawas sekolah (Bustami et al., 2012). Perencanaan adalah salah satu peran kepala sekolah sebagai administrator. Salah satunya adalah perencanaan program. Kegiatan perencanaan program di masa pandemi covid-19 dilakukan untuk menjaga keberlangsungan penyelenggaraan pendidikan agar tetap bertahan. Hal ini dilakukan melalui merancang program, mengelola anggaran, dan menyusun prosedur, menyusun skala prioritas. Ini semua dilakukan untuk mencukupi semua kebutuhan pelayanan sekolah (Supriadi, 2020).

\section{Proses Pembelajaran}

Proses pembelajaran pada PAUD dirancang sesuai dengan tumbuh kembang anak. Mengacu pada Standar Nasional Pendidikan Anak Usia Dini (SN PAUD), standar proses adalah kriteria tentang pelaksanaan pembelajaran pada satuan atau program PAUD dalam rangka membantu pemenuhan tingkat pencapaian perkembangan yang sesuai dengan tingkat usia anak. Perkembangan anak adalah salah satu kajian bagaimana anak berubah waktu lahir sampai usia delapan tahun. Bagaimana cara anak belajar dan berkembang, adalah bagian dari praktek profesional pendidik. Untuk itu, berkomunikasi, mengevaluasi pembelajaran, dan memberi bimbingan merupakan dimensi penting dari peran profesional pendidik.

Pemimpin dalam kegiatan proses pembelajaran ini dipapakan oleh Mulyasa berperan sebagai edukator, manajer, administrator, supervisor, leader, inovator, dan motivator bagi para anggotanya (Supriadi, 2020). Pemimpin sebagai educator untuk meningkatkan kompetensi guru (Rusdiana, 2018). Pemimpin sebagai manajer, diadaptasi dari teori Harold Koontz, Heinz Weihrich adalah mereka yang melaksanakan tugas-tugas dan fungsi-fungsi manajemen (J Winardi, 2015). Pemimpin sebagai administrator adalah pemimpin yang bertanggungjawab dalam pengelolaan administrasi untuk keberhasilan guru dalam mengajar (Devy, 2018). Pemimpin sebagai supervisor untuk membangkitkan dan merangsang guruguru dan pegawai sekolah agar dalam menjalankan tugas sehari-hariya dijalankan dengan baik (Hanafiah, 2018). Pemimpin sebagai inovator untuk memberikan keteladanan (Putra, 2020). Pemimpin sebagai motivator untuk meningkatkan kinerja guru (Suryosukmono, 2020).

\section{Metode Pengajaran}

Metode pengajaran pada PAUD mengacu pada Standar Nasional Pendidikan Anak Usia Dini (SN PAUD), yaitu Peraturan Menteri Pendidikan dan Kebudayaan Republik Indonesia Nomor 137 Tahun 2014. Metode pengajaran dapat melalui metode bercerita 
(Setiantono, 2012), metode domonstrasi untuk meningkatkan kemampuan kognitif anak (Nonik et al., 2013) dan meningkatkan perkembangan motorik halus (Purnamasari et al., 2014), metode gerak dan lagu (Uzer, 2019), metode karya wisata untuk meningkatkan kemampuan becerita anak, (Ayuandia et al., 2017) dan untuk mengembangkan motorik kasar (Sudjono \& Kusumastuti, 2017).

\section{Struktur Organisasi}

Pengorganisasian, merupakan pengaturan seluruh komponen untuk mencapai tujuan.

Pendidikan membutuhkan perencanaan, pengelolaan, pengorganisasian, dan pengkoordinasian (Pananrangi \& Rasyid, 2017). Struktur organisasi memiliki pengaruh terhadap efektivitas organisasi (Gammahendra, 2014). Struktur organisasi yang jelas akan menciptakan iklim organisasi yang positif (Karwanto \& Ramadhan, 2020). Struktur organisasi yang belum optimal solusinya adalah dilakukan perencanaan, pengelolaan, pengorganisasian, dan pengkoordinasian untuk memberikan pengaruh terhadap efektivitas organisasi. Dengan menyusun dan mengatur struktur organisasi yang jelas, akan menciptakan iklim yang positif pada organisasi.

\section{Memiliki Kearifan}

Pemimpin yang memiliki kearifan identik dengan pemimpin yang bijaksana. Pemimpin yang bijaksana menyadari perlu adanya keselarasan (Chrisharyanto et al., 2014), cakap bergaul baik dengan bawahan maupun dengan atasan (Syamsuriadi, 2019). Dampak dari kepemimpinan yang bijaksana adalah adanya friendship dan inovasi di tempat kerja (Abdulmuhsin \& Tarhini, 2020).

\section{Visi}

Pemimpin menyampaikan visi. Kepemimpinan visioner tipenya diantaranya adalah pencipta, pendakwah, idealis, dan peramal (Westley \& Mintzberg, 1989). Robbins \& Judge mendeskripsikan kepemimpinan visioner adalah kepemimpinan untuk menciptakan dan menegaskan visi (Muttaqijn, 2015). Menetapkan visi yang jelas salah satunya melalui pembentukan struktur organisasi. Pembentukan ini bertujuan untuk memperjelas jobdesk yang mengarah pada visi yang sudah ditentukan.

Sejalan dengan penelitian oleh Sukriadi Eri Hidayat dengan judul "Pengaruh Kepemimpinan Visioner Dan Motivasi Kerja Terhadap Kepuasan Kerja" bahwa seorang pemimpin yang visioner memiliki visualizing (gambaran yang jelas apa dan kapan akan dicapai), pemimpin yang memiliki futuristic thinking (memikirkan apa yang akan dicapai di masa depan). Pemimpin memiliki showing foresight yaitu pemimpin yang memiliki perencanaan, pertimbangan, dan prosedur untuk mengantisipasi apabila muncul faktor lain yang kemungkinan akan mempengaruhi perencanaan (Sukriadi, 2018).

\section{Melatih}

Pemimpin melatih orang berpikir jernih dan adil bagi diri mereka sendiri dan orang lain. Leaderhip coaching merupakan salah satu sarana untuk mencapai tujuan dalam kepemimpinan pendidikan (Wise \& Hammack, 2011). Proses pembelajaran yang belum efektif, dapat diatasi melalui pelatihan. Pelatihan untuk guru PAUD sebagai contoh pelatihan memilih dan memanfaatkan media dan sumber belajar yang sesuai dengan perkembangan anak. Metode yang digunakan selama pembelajaran masa covid-19 adalah physical distancing (menjaga jarak fisik) dan social distancing (menjaga jarak sosial) untuk memutus rantai penularan (Pramana, 2020). Salah satu pembelajaran untuk memutus rantai penularan yaitu pembelajaran daring melalui tutorial secara online menggunakan aplikasi youtube (Ayuni et al., 2020).

Sejalan dengan penelitian oleh Kim bahwa prajabatan pendidikan guru di pendidikan anak usia dini dirancang untuk memberikan kesempatan kepada guru dan siswa untuk belajar 
dan mengajar secara online pada masa pandemi covid-19 (Kim, 2020). Untuk mendukung pembelajaran pada PAUD di masa pandemi covid-19, pendidik diharuskan mengajar dengan teknologi digital, dilakukan 20 sampai 30 menit tiap sesi pertemuan (Hu et al., 2021). Salah satu pendukung pembelajaran yang menggunakan teknologi digital adalah aplikasi edutainment, yang memuat konten yang sesuai dengan standar isi pada SN PAUD (Zamzami, 2021).

Beberapa hal yang menjadi keterbatasan penelitian adalah terkait dengan metode penelitian, teknik pengumpulan data, dan sampel yang terlibat. Pada metode penelitian, menggunakan pendekatan kualitatif, sehingga hal-hal yang belum tergali dalam penelitian ini dilanjutkan oleh peneliti berikutnya yang berkenan meneliti pada subyek pnelitian ini.

\section{SIMPULAN}

Kepemimpinan PAUD pada masa pandemi covid 19 sangat dibutuhkan kebijaksanaan dan kecendekiaan untuk mencapai kualitas pendidik. Pemimpin selalu berupaya mengkomunikasikan visi sebagai salah satu cara untuk mencapai tujuan, hal ini dapat dliakukan melalui komunikasi baik dengan guru, orangtua wali murid, maupun stakeholder. Selain itu secara terus menerus menyampaikan visi adalah salah satu dari upaya untuk mencapai tujuan lembaga. Kepemimpinan dapat diimplementasikan keefektifannya melalui perencanaan, pengorganisasian, pengarahan dan pengawasan. Faktor ini dikaitkan dengan hasil belajar siswa dan kurikulum, proses pembelajaran, dan metode pengajaran. Perencanaan, pengorganisasian, pengarahan, dan pengawasan ini, dikaitkan dengan hasil belajar siswa dan kurikulum, proses pembelajaran, dan metode pengajaran dilaksanakan bersama guru dan wali murid serta unsur sekolah.

\section{UCAPAN TERIMA KASIH}

Ucapan terima kasih kepada Pimpinan, Kepala Sekolah dan Guru-Guru PAUD di Kabupaten Indamayu Jawa Barat yang telah memberikan banyak kontribusi dalam penelitian ini. Selain itu, penulis mengucapkan terima kasih dan penghargaan yang setinggi-tingginya kepada para reviewer dan editor yang telah mereview dan menelaah artikel ini. Ucapan terima kasih ditujukan pula kepada dewan redaksi Jurnal Obsesi Pendidikan Anak Usia Dini, atas diterbitkannya artikel ini.

\section{DAFTAR PUSTAKA}

Abdulmuhsin, A. A., \& Tarhini, A. (2020). Impact of wise leadership, workplace friendships on open innovation in family firms: a developing country perspective. Journal of Family Business Management. https://doi.org/10.1108/JFBM-04-2020-0028

Afriansyah, H., \& Pratiwi, D. (2020). Kepemimpinan pendidikan.

Alban-Metcalfe, J., \& Alimo-Metcalfe, B. (2013). Reliability and validity of the "leadership competencies and engaging leadership scale." International Journal of Public Sector Management. https://doi.org/10.1108/09513551311294281

Allen, M. B., \& Mirsaeidi, M. (2020). Health and Economy in COVID-19 Era: a plan for reconstituting long-term economic security. Frontiers in Public Health, 8, 235. https://doi.org/10.3389/fpubh.2020.00235

Ayuandia, N., Saparahayuningsih, S., \& Ardina, M. (2017). Meningkatkan Keterampilan Berbicara Melalui Metode Karyawisata Pada Anak Kelompok B Lab School PAUD UNIB Kota Bengkulu. Jurnal Ilmiah Potensia, 2(1), 33-38.

Ayuni, D., Marini, T., Fauziddin, M., \& Pahrul, Y. (2020). Kesiapan guru TK menghadapi pembelajaran daring masa pandemi COVID-19. Jurnal Obsesi: Jurnal Pendidikan Anak Usia Dini, 5(1), 414-421. https://doi.org/10.31004/obsesi.v5i1.579 
Baharuddin, B., Elihami, E., Arifin, I., \& Wiyono, B. B. (2017). Kepemimpinan Moral Spiritual Kepala Paud Dalam Meningkatkan Pembelajaran Karakter Anak Usia Dini. Jurnal Pendidikan Islam, 8(2), 103-122. https:// doi.org/10.31219/osf.io/6wj5s

Brundrett, M., Burton, N., \& Smith, R. (2003). Leadership in education. Sage.

Bustami, B., Murniati, M., \& Harun, C. Z. (2012). Manajemen Pendidikan PAUD Al-Fath Sabang. Jurnal Administrasi Pendidikan Program Pascasarjana Unsyiah, 1(2), 72176.

Chrisharyanto, H., Rahmania, T., \& Kertamuda, F. E. (2014). Konsep pemimpin nasional yang baik: Survey pada masyarakat Jakarta. Jurnal SosioHumaniora, 5(1).

Devy, J. (2018). Peran Kepala Madrasah Sebagai Administrator Di MTs Negeri 2 Bandar Lampung. UIN Raden Intan Lampung.

Dias, M. J. A., Almodóvar, M., Atiles, J. T., Vargas, A. C., \& Zúñiga León, I. M. (2020). Rising to the Challenge: Innovative early childhood teachers adapt to the COVID-19 era. Childhood Education, 96(6), 38-45. https:/ / doi.org/10.1080/00094056.2020.1846385

Djafri, N. (2020). Pengaruh Gaya Kepemimpinan dan Budaya Kerja Kepala Sekolah di Pendidikan Anak Usia Dini. Jurnal Obsesi: Jurnal Pendidikan Anak Usia Dini, 4(2), 940-950.

https:// doi.org/10.31004/obsesi.v4i2.494

Duryat, M. (2016). Kepemimpinan Pendidikan (meneguhkan legitimasi dalam berkontestasi di bidang pendidikan).

Ekosiswoyo, R. (2016). Kepemimpinan kepala sekolah yang efektif kunci pencapaian kualitas pendidikan. Jurnal Ilmu Pendidikan, 14(2).

Gammahendra, F. (2014). Pengaruh struktur organisasi terhadap efektivitas organisasi (studi pada persepsi pegawai tetap Kantor perwakilan Bank Indonesia Kediri). Jurnal Administrasi Bisnis, 7(2).

Hanafiah, M. A. (2018). Kepala Sekolah Sebagai Pemimpin dan Supervisor. Hikmah, 15(1), 8692.

Harahap, S. R. (2020). Proses Interaksi Sosial Di Tengah Pandemi Virus Covid 19. ALHIKMAH: Media Dakwah, Komunikasi, Sosial Dan Budaya, 11(1), 45-53. https://doi.org/10.32505/hikmah.v11i1.1837

Hu, X., Chiu, M. M., Leung, W. M. V., \& Yelland, N. (2021). Technology integration for young children during COVID-19: Towards future online teaching. British Journal of Educational Technology. https://doi.org/10.1111/bjet.13106

J Winardi, S. E. (2015). Manajemen perilaku organisasi. Prenada Media.

James, N., \& Thériault, V. (2020). Adult education in times of the COVID-19 pandemic: Inequalities, changes, and resilience. Taylor \& Francis. https:// doi.org/10.1080/02660830.2020.1811474

Karwanto, K., \& Ramadhan, R. . (2020). Membangun iklim Organisasi Sekolah Melalui Peran Kepala Sekolah Dalam Upaya Meningkatkan Kinerja Guru. Inspirasi Manajemen Pendidikan, 8(3), 285-297.

Kim, J. (2020). Learning and Teaching Online During Covid-19: Experiences of Student Teachers in an Early Childhood Education Practicum. International Journal of Early Childhood, 52(2), 145-158. https://doi.org/10.1007/s13158-020-00272-6

Morrison, G. S. (2012). Dasar-dasar pendidikan anak usia dini (PAUD). Jakarta: Indeks.

Muttaqijn, M. I. (2015). Pengaruh Kepemimpinan Visioner, Komunikasi Organisasi Dan Kompetensi Karyawan Terhadap Kepuasan Kerja. Jurnal Dinamika UMT, 1(1), 27-38. https:// doi.org/10.31000/dinamika.v1i1.506

Nasution, W. N. (2016). Kepemimpinan pendidikan di sekolah. Jurnal Tarbiyah, 22(1). https://doi.org/10.29240/jpd.v1i1.218

Nonik, N. N., Raga, I. G., \& Murda, I. N. (2013). Penerapan Metode Demonstrasi dengan Media Kartu Gambar untuk Meningkatkan Kemampuan Kognitif Anak Kelompok A di PAUD Widya Dharma Bondalem Tejakula. Jurnal Pendidikan Anak Usia Dini Undiksha, 1(1). 
Northouse, P. G. (2021). Leadership: Theory and practice. SAGE Publications, Incorporated. Oplatka, I. (2016). "Irresponsible Leadership" and Unethical Practices in Schools: A Conceptual Framework of the "Dark Side" of Educational Leadership. In The dark side of leadership: Identifying and overcoming unethical practice in organizations. Emerald Group Publishing Limited. https://doi.org/10.1108/S1479-366020160000026001

Pananrangi, \& Rasyid, A. (2017). Manajemen Pendidikan (Vol. 1). Celebes Media Perkasa.

Pramana, C. (2020). Pembelajaran Pendidikan Anak Usia Dini (PAUD) Dimasa Pandemi Covid-19. Indonesian Journal of Early Childhood: Jurnal Dunia Anak Usia Dini, 2(2), 115-123.

https://doi.org/10.31004/obsesi.v5i1.592

Pranita, U., Kurniah, N., \& Suprapti, A. (2018). Pelaksanaan Supervisi Klinis Kepala Sekolah Pendidikan Anak Usia Dini Islam Terpadu Kota Bengkulu (Studi Deskriptif Kualitatif di PAUD IT Auladuna Kota Bengkulu). Jurnal Ilmiah Potensia, 3(1), 54-65.

Purnamasari, N. K. N., Negara, I. G. A. O., Ke, S. P. M., \& Suara, I. M. (2014). Penerapan Metode Demonstrasi Melalui Kegiatan Melipat Kertas (Origami) Untuk Meningkatkan Perkembangan Motorik Halus Anak Tk Kemala Bhayangkari 1 Denpasar. Jurnal Pendidikan Anak Usia Dini Undiksha, 2(1).

Putra, J. A. (2020). Peran Kepala Sekolah Sebagai Inovator di Sekolah Menengah Pertama Negeri Kota Pariaman. Jurnal Bahana Manajemen Pendidikan, 2(1), 347-355.

Rusdiana, E. (2018). Peran Kepemimpinan Kepala Sekolah Sebagai Educator dalam Meningkatkan Kompetensi Guru. Indonesian Journal of Education Management \& Administration Review, 2(1), 231-236. https:// doi.org/10.30762/ed.v1i2.449

Satrianingrum, A. P., \& Prasetyo, I. (2021). Persepsi guru dampak pandemi Covid-19 terhadap pelaksanaan pembelajaran daring di PAUD. Jurnal Obsesi: Jurnal Pendidikan Anak Usia Dini, 5(1), 633-640. https://doi.org/10.31004/obsesi.v5i1.574

Setiantono, T. (2012). Penggunaan Metode Bercerita bagi Anak Usia Dini di PAUD Smart Little Cilame Indahbandung. EMPOWERMENT: Jurnal Ilmiah Program Studi Pendidikan Luar Sekolah, 1(2), 18-23.

Sudjono, E. T. K., \& Kusumastuti, E. (2017). Proses Pembelajaran Gerak dan Lagu yang Kreatif Berdasarkan Kurikulum 2013 di TK Miryam Semarang. Jurnal Seni Tari, 6(2).

Sudrajat, C. J., Agustin, M., Kurniawati, L., \& Karsa, D. (2020). Strategi Kepala TK dalam meningkatkan mutu pendidikan pada masa pandemi Covid 19. Jurnal Obsesi: Jurnal Pendidikan Anak Usia Dini, 5(1), 508-520. https://doi.org/10.31004/obsesi.v5i1.582

Sukriadi, E. H. (2018). Pengaruh Kepemimpinan Visioner Dan Motivasi Kerja Terhadap Kepuasan Kerja. THE Journal: Tourism and Hospitality Essentials Journal, 8(2), 139146.

https:/ / doi.org/10.17509/thej.v8i2.13747

Summers, R. C., \& Sutherland, I. E. (2015). Prekindergarten Interventions and Instructional Leadership in Small and Mid-Sized Urban School Districts. In Leading Small and MidSized Urban School Districts. Emerald Group Publishing Limited. https://doi.org/10.1108/S1479-366020150000022019

Supriadi, O. (2020). Peranan Kepala PAUD dalam Penyelenggaraan Pendidikan Sebelum dan Saat Terjadi Pandemi Covid-19. Jurnal Obsesi: Jurnal Pendidikan Anak Usia Dini, 5(1), 841-856.

https://doi.org/10.31004/obsesi.v5i1.727

Suryana, D. (2013). Pendidikan Anak Usia Dini: Teori Dan Praktik Pembelajaran.

Suryosukmono, G. (2020). Kepemimpinan Transformasional, Kepuasan Kerja Dan Komitmen Organisasi Sebagai Motivator Kinerja Pegawai Negeri Sipil. Managament Insight: Jurnal Ilmiah Manajemen, 15(1), 1-18. https://doi.org/10.33369/insight.15.1.1-18

Syamsuriadi, S. (2019). Self Management Concept Dalam Kepemimpinan Lembaga Pendidikan. Adaara: Jurnal Manajemen Pendidikan Islam, 9(2), 871-879. https://doi.org/10.35673/ajmpi.v9i2.423 
Thornton, K. (2014). Mentors as educational leaders and change agents. International Journal of Mentoring and Coaching in Education, 3(1), 18-31. https:// doi.org/10.1108/IJMCE-07-2013-0038

Usman, H., \& Akbar, P. S. (2018). Metodologi penelitian sosial. Bumi Aksara.

Uzer, Y. (2019). Implementasi pembelajaran bahasa inggris anak melalui metode gerak dan lagu untuk anak paud. PERNIK: Jurnal Pendidikan Anak Usia Dini, 2(2), 187-193. https:// doi.org/10.31851/pernik.v2i01.3117

Wang, M., Ho, D., Lu, J., \& Yang, D. (2020). Constructing early childhood leadership models in China: a mixed-methods study. Journal of Educational Administration. https:// doi.org/10.1108/JEA-09-2019-0149

Wardani, A., \& Ayriza, Y. (2020). Analisis kendala orang tua dalam mendampingi anak belajar di rumah pada masa pandemi Covid-19. Jurnal Obsesi: Jurnal Pendidikan Anak Usia Dini, 5(1), 772. https://doi.org/10.31004/obsesi.v5i1.705

Westley, F., \& Mintzberg, H. (1989). Visionary leadership and strategic management. Strategic Management Journal, 10(S1), 17-32. https:/ / doi.org/10.1002/smj.4250100704

Wise, D., \& Hammack, M. (2011). Leadership coaching: Coaching competencies and best practices. Journal of School Leadership, 21(3), 449-477. https:// doi.org/10.1177/105268461102100306

Zamzami, E. M. (2021). Aplikasi Edutainment Pendukung Pembelajaran Jarak Jauh TK Merujuk Standar Nasional PAUD. Jurnal Obsesi: Jurnal Pendidikan Anak Usia Dini, 5(2), 985-995. https:// doi.org/10.31004/obsesi.v5i2.750 